\title{
Evaluation of the in vivo effect of argon plasma coagulation with prior submucosal injection (Hybrid APC) in the esophagus of pigs
}

\section{Satoshi Abiko}

Kushiro Rosai Hospital https://orcid.org/0000-0002-0962-8342

\section{Yuichi Shimizu}

Hokkaido University Hospital

Shunsuke Ohnishi ( $\nabla$ sonishi@pop.med.hokudai.ac.jp)

https://orcid.org/0000-0003-1194-4149

\section{Marin Ishikawa}

Hokkaido University Hospital

\section{Kana Matsuda}

Hokkaido University Graduate School of Medicine

Shuichi Miyamoto

Hokkaido University Graduate School of Medicine

\section{Momoko Tsuda}

Hokkaido University Graduate School of Medicine

\section{Takeshi Mizushima}

Hokkaido University Graduate School of Medicine

\section{Keiko Yamamoto}

Hokkaido University Hospital

\section{Shoko Ono}

Hokkaido University Hospital

\section{Takahiko Kudo}

Hokkaido University Hospital

\section{Naoya Sakamoto}

HOkkaido University Graduate School of Medicine

\section{Research article}

Keywords: argon-plasma coagulation, submucosal injection, esophageal neoplasms

Posted Date: July 16th, 2019

DOI: https://doi.org/10.21203/rs.2.11418/v1 
License: (c) (i) This work is licensed under a Creative Commons Attribution 4.0 International License. Read Full License 


\section{Abstract}

Background Although argon-plasma coagulation (APC) is useful for treating early gastrointestinal cancer, safer ablation for oesophageal cancer is needed because the esophageal wall is very thin. The efficacy of APC with prior submucosal injection of saline (hybrid APC) by using a resected oesophagus of pig has been reported, but there has been no study in which the effects, biological reactions and delayed adverse effects of hybrid APC were evaluated. In this study, we evaluated the histological efficacy of APC with prior submucosal injection of saline (hybrid APC) by using an in vivo porcine model. Methods APC alone and hybrid APC were performed. Various settings of argon were used. The pigs were sacrificed after treatment (study 1) and 1 week after treatment (study 2). Histological evaluation of the deepest spot of coagulation from the basal layer (study 1 ) and non-atrophic muscle zone (study 2 ) in resected specimens was performed. Type A damage was defined as superficial tissue damage of the tunica mucosa, whereas type B damage was defined as an injury pattern limited to the tunica muscularis. The depths of type A and type $B$ damage were measured in study 1 . Immunohistochemical analysis was also performed in study 2. Results (study 1) Hybrid APC except for that at an excessive setting could prevent type B damage of the muscle layer. Standard APC at any setting could not prevent type B damage of the muscle layer. Results (study 2) The non-atrophic muscle zone was significantly larger in the hybrid APC group. Immunohistochemical analysis showed that the numbers of activated myofibroblasts and infiltrating neutrophils and macrophages were significantly smaller in the hybrid APC group than in the standard APC group. Conclusion APC following submucosal injection of saline contributes to sufficient and safe coagulation for oesophageal lesions.

\section{Abstract}

Background: Although argon-plasma coagulation (APC) is useful for treating early gastrointestinal cancer, safer ablation for esophageal cancer is needed because the esophageal wall is very thin. The efficacy of APC with prior submucosal injection of saline (hybrid APC) by using a resected esophagus of pig has been reported, but there has been no study in which the effects, biological reactions and delayed adverse effects of hybrid APC were evaluated. In this study, we evaluated the histological efficacy of APC with prior submucosal injection of saline (hybrid APC) by using an in vivo porcine model.

Methods: APC alone and hybrid APC were performed. Various settings of argon were used. The pigs were sacrificed after treatment (study 1 ) and 1 week after treatment (study 2). Histological evaluation of the deepest spot of coagulation from the basal layer (study 1) and non-atrophic muscle zone (study 2) in resected specimens was performed. Type A damage was defined as superficial tissue damage of the tunica mucosa, whereas type $B$ damage was defined as an injury pattern limited to the tunica muscularis. The depths of type A and type B damage were measured in study 1 . Immunohistochemical analysis was also performed in study 2 .

Results (study 1): Hybrid APC except for that at an excessive setting could prevent type B damage of the muscle layer. Standard APC at any setting could not prevent type B damage of the muscle layer. 
Results (study 2): The non-atrophic muscle zone was significantly larger in the hybrid APC group. Immunohistochemical analysis showed that the numbers of activated myofibroblasts and infiltrating neutrophils and macrophages were significantly smaller in the hybrid APC group than in the standard APC group.

Conclusions: APC following submucosal injection of saline contributes to sufficient and safe coagulation for esophageal lesions.

Key words: argon-plasma coagulation, submucosal injection, esophageal neoplasms

\section{Background}

Endoscopic mucosal resection (EMR) or endoscopic submucosal dissection (ESD) has been regarded as the best treatment for patients with early-stage gastrointestinal cancer. ${ }^{1-4}$ However, argon plasma coagulation (APC) is often used for treating those patients due to the poor general condition of the patients or status of the lesions. ${ }^{5-8}$ It has been reported that APC treatment for esophageal cancer has a complete cure rate of $94.7 \%,{ }^{5}$ and it was shown in another study that there is a local recurrence rate of $9.5 \%{ }^{6}$ In addition, it has been reported that radiofrequency ablation, a tissue destruction method similar to APC, has a complete cure rate of $86.0 \%{ }^{7}$ We have recently reported good long-term outcomes for patients with esophageal squamous cell carcinoma who underwent APC with a local recurrence rate of $3.6 \%$ and 5-year cause-specific survival rate of $100 \% .{ }^{8}$ In that study, we performed submucosal saline injection before APC (hybrid APC) in all cases, and we hypothesized that submucosal injection of saline prior to APC would result in uniform and sufficient coagulation and would contribute to a good outcome. Although the efficacy of APC with prior submucosal injection (hybrid APC) by using a resected esophagus of pig has been reported, ${ }^{9}$ there has been no study in which the effects, biological reactions and delayed adverse effects of hybrid APC were evaluated.

In this study, we evaluated the efficacy of hybrid APC in the esophagus histologically by comparing it with the efficacy of standard APC using an in vivo porcine model.

\section{Methods}

\section{Animals}

The experimental protocol was approved by the Animal Care and Use Committee of Hokkaido University. Female domestic pigs (20-25 kg; Sankyo Labo Service, Tokyo, Japan) were used in the study.

\section{APC}

The pigs were anesthetized, APC was performed with continuous monitoring and a gastrointestinal endoscope was used as described previously. ${ }^{9}$ The markings for creating APC lesions were placed with a 
flexible APC applicator of $2.3 \mathrm{~mm}$ in diameter (ERBE Germany, Tübingen, Germany) on the esophagus as the lesion $\left(33 \mathrm{~cm}^{2}\right)$ using an electrosurgical generator and automatically regulated argon source (ERBE VIO300D/APC 2; ERBE Germany, Tübingen, Germany). All APC procedures were performed by using the forced APC mode, and hybrid APC and direct APC without submucosal injection of saline (standard APC) were performed in various settings. For hybrid APC, injection of saline was into the submucosal layer beneath the lesion was performed using a 25-gauge needle (Top Corporation), and the lesion was ablated with APC. Although it is difficult to keep the APC applicator in the same state, we tried as much as possible to keep a constant distance between the applicator and tissue (about $2 \mathrm{~mm}$ and angle of 20 degrees). All APC procedures were performed by one endoscopist (S.A.) who had experience of more than 50 human APC cases and more than 150 human ESD cases, including cases in the head and neck, esophagus, stomach, and colon. For postoperative care, all of the pigs were given food after APC as described previously. ${ }^{9}$ The pigs were sacrificed immediately after APC in study 1 and 1 week after APC in study 2. All of the pigs were sacrificed by intravenous injection of $20 \mathrm{~mL}$ of $15 \%$ potassium chloride (Terumo, Tokyo, Japan) after general anesthesia.

\section{Histological and immunohistochemical examinations}

The anterior neck and abdomen of each of the pigs were incised, and transhiatal esophagectomy was performed. The resected esophagus was fixed as described previously. ${ }^{9}$ Pathological evaluation of the deepest spot of coagulation from the basal layer (study 1) and non-atrophic muscle zone (study 2) in the resected specimens was performed (NDP View2 software; Hamamatsu, Japan) in a blinded manner.

According to a report by Georg at al., ${ }^{10}$ superficial tissue damage of the tunica mucosa was classified as type $A$ damage and an injury pattern limited to the tunica muscularis was classified as type $B$ damage in study 1 (Figure 1). In study 2 , the tissue sections were stained as described previously. ${ }^{9}$

\section{Statistical analysis}

JMP® Pro 12.0.1 (SAS Institute, Inc., Cary, NC, USA) was used for data analysis. Data were expressed and parameters in the two groups were compared as described previously. ${ }^{9}$

\section{Results}

Study 1: Histological analysis of the esophagus immediately after hybrid APC and standard APC.

Representative histological sections showing the depth of damage are presented in Figure 2. In study 1 , hybrid APC except for that with an excessive setting (argon gas flow set at $2.0 \mathrm{~L} / \mathrm{min}, 3$ seconds, 60 watts) was able to prevent type B damage of the muscle layer. On the other hand, standard APC was not able to prevent type $B$ damage of the muscle layer in any of the settings.

Shallow and uniform coagulation was achieved immediately after hybrid APC. 
Study 2: Histological analysis of the esophagus 1 week after hybrid APC and standard APC (Tables 1, 2 and 3).

There was a larger non-atrophic muscle zone in the hybrid APC group than in the standard APC group (Figure $3 \mathrm{a}$ and $3 \mathrm{~b}$ ). The non-atrophic muscle zone was significantly larger in the hybrid APC group than in the standard APC group (Figure 3c, Tables 2 and 3).

\section{Immunohistochemical analysis}

Immunohistochemical analysis showed that the numbers of activated myofibroblasts (Figure 4a) and infiltrating neutrophils (Figure $4 \mathrm{~b}$ ) were significantly decreased in the hybrid APC group compared to those in the standard APC group (Table 3). However, there was no significant difference between the two groups in capillary density (Figure $4 \mathrm{~d}$, Table 3 ).

\section{Discussion}

In this study, we investigated the effect of submucosal injection of saline prior to APC in the esophagus of pigs and we found that (1) shallow and uniform coagulation was achieved immediately after hybrid APC, (2) atrophic change in the muscle zone at 1 week after hybrid APC was less than that at 1 week after standard APC, and (3) the numbers of activated myofibroblasts and infiltrating neutrophils in the esophagus at 1 week after hybrid APC were smaller than those at 1 week after standard APC.

Conventional studies using a resected esophagus of pig showed that tissue damage caused by APC may be limited up to the submucosal layer under the conditions commonly used ${ }^{12,13}$ and that submucosal injection of saline prior to APC may be more effective for preventing deep tissue damage. ${ }^{13-15}$ However, it has been suggested that tissue response to damage in an in vivo model may be different from that in extracted tissue. ${ }^{16}$ Fujishiro et al. performed APC with the same settings in the stomachs of the two pigs and they sacrificed one pig immediately after the treatment and the other pig 1 week after the treatment. The pig sacrificed immediately after APC had an ulcer extending to the submucosal layer, and pathological evaluation of the depth of coagulation from the basal layer was performed only using type $A$ damage. However, the pig sacrificed 1 week after APC had a deep ulcer extending to the deeper muscle layer. ${ }^{17}$

Regarding the safety of APC, it has been reported that the incidence of perforations and strictures was less than $1 \% .{ }^{18-24}$ However, unexpected deep ulcers or stenosis after APC at follow-up endoscopic examination have been reported. ${ }^{20,23,25,26}$ Therefore, we hypothesized that type $B$ damage is true tissue damage. In study 1 , we examined the depths of type $A$ damage and type $B$ damage in pathological examinations. In study 2, we performed histological evaluation of the non-atrophic muscle zone to investigate the degree of damage of the muscle layer. In study 1, hybrid APC except for that at an excessive setting (argon gas flow set at $2.0 \mathrm{~L} / \mathrm{min}, 3$ seconds, 60 watts) was able to prevent type $B$ damage of the muscle layer. However, standard APC was not able to prevent type B damage of the 
muscle layer at any of the settings. In study 2, the degree of atrophy of the muscle layer was less after hybrid APC. Kawada et al. reported that APC-subepithelial ablation without submucosal injection is a safe and curative therapy. ${ }^{27}$ After the initial ablation, they exfoliated the epithelium and then performed a second ablation. They performed APC-subepithelial ablation in resected esophagi of pigs and they reported that the technique was effective, though they did not evaluate biological reactions or delayed adverse effects.

Elasticity and compliance are reduced by inflammation and fibrosis of the esophageal wall after ESD, resulting in postoperative stricture. ${ }^{28}$ Fibrosis is excessive accumulation of extracellular matrix proteins including collagen that are produced by activated myofibroblasts during the wound healing process. ${ }^{29}$ In addition, neutrophils and macrophages at the site of tissue damage release various of cytokines, which activate resident fibroblasts into myofibroblasts. ${ }^{30,31}$ In the present study, submucosal injection of saline prior to APC resulted in decreases in the numbers of activated myofibroblasts and infiltrating neutrophils in the esophagus 1 week after APC as the key mechanism by which stricture formation was prevented during the wound healing process. Although hybrid APC did not decrease the number of macrophages, it may contribute to the prevention of stenosis after APC.

Our study has two limitations, One limitation is the small sample size. The other limitation is that small pigs $(20-25 \mathrm{~kg})$ were used in this study. Because of the difference in species, the wound healing process observed in this study may not be able to be extrapolated to humans.

\section{Conclusions}

In conclusion, submucosal injection of saline prior to APC contributes to safe and sufficient coagulation for esophageal lesions.

\section{Abbreviations}

APC, argon-plasma coagulation; EMR, endoscopic mucosal resection; ESD, endoscopic submucosal dissection

\section{Declarations}

\section{Ethics approval and consent to participate}

The in vitro study protocol was approved by the ethical review board of Hokkaido University Hospital.

\section{Consent for publication}

Not applicable.

\section{Availability of data and material}


Publication of our data does not comprise anonymity or confidentiality.

\section{Competing interests}

The authors declare that they have no competing interests.

\section{Funding}

No funding to declare.

\section{Authors' contributions}

SA, SO, MT, and TK performed the experiments and analyses and drafted the

manuscript, SA performed APC, SA performed analyses, YS, SO, MI, KM, SM, KY, SO, TK and NS supervised the entire project. All authors have read and approved the final manuscript.

\section{Acknowledgements}

We are grateful to all pigs in this study.

\section{References}

1. Toyonaga T, Man-i M, East JE, Nishino E, Ono W, Hirooka T, et al. 1,635 Endoscopic submucosal dissection cases in the esophagus, stomach, and colorectum: complication rates and long- term outcomes. Surg Endosc. 2013;27:1000-8. 2. Mizushima T, Kato M, Iwanaga I, Sato F, Kubo K, Ehira N, et al. Technical difficulty according to location, and risk factors for perforation, in endoscopic submucosal dissection of colorectal tumors. Surg Endosc. 2015;29:133-9. 3. Kosaka T, Endo M, Toya Y, Abiko Y, Kudara N, Inomata $\mathrm{M}$, et al. Long-term outcomes of endoscopic submucosal dissection for early gastric cancer: a single-center retrospective study. Dig Endosc. 2014;26:183-1. 4. Takahashi H, Arimura Y, Masao $\mathrm{H}$, Okahara S, Tanuma T, Kodaira J, et al. Endoscopic submucosal dissection is superior to conventional endoscopic resection as a curative treatment for early squamous cell carcinoma of the esophagus (with video). Gastrointest Endosc. 2010;72:255-64. 5. Min BH, Kim ER, Lee JH, Kang KJ, Rhee PL, Kim JJ, et al. Feasibility and efficacy of argon plasma coagulation for early esophageal squamous cell neoplasia. Endoscopy. 2013; 45: 575-8. 6. Tahara K, Tanabe S, Ishido K, Higuchi K, Sasaki T, Katada C, et al. Argon plasma coagulation for superficial esophageal squamous-cell carcinoma in high-risk patients. World $\mathrm{J}$ Gastroenterol. 2012;18:5412-7. 7. Bergman JJ, Zhang YM, He S, Weusten B, Xue L, Fleischer DE, et al. Outcomes from a prospective trial of endoscopic radiofrequency ablation of early squamous cell neoplasia of the esophagus. Gastrointest Endosc. 2011;74:1181-90. 8. Abiko S, Shimizu Y, Yamamoto K, Ishikawa M, Matsuda K, Tsuda M, et al. Long-term outcome for patients with esophageal squamous cell carcinoma who underwent Argon Plasma Coagulation. Endoscopy. 2018; doi:10.1055/s-0038-1637126. 9. Manner H, Neugebauer A, Scharpf M, Braun K, May A, Ell C, et al. The tissue effect of argon-plasma coagulation with prior submucosal injection (Hybrid-APC) versus standard APC: A randomized ex-vivo study. United European Gastroenterol J. 2014;2:383-90. 10. Mizushima T, Ohnishi S, Hosono H, 
Yamahara K, Tsuda M, Shimizu Y, et al. Oral administration of conditioned medium obtained from mesenchymal stem cell culture prevents subsequent stricture formation after esophageal submucosal dissection in pigs. Gastrointest Endosc. 2017;86:542- 52. 11. Kähler GF, Szyrach MN, Hieronymus A, Grobholz R, Enderle MD. Investigation of the thermal tissue effects of the argon plasma coagulation modes "pulsed" and "precise" on the porcine esophagus, ex vivo and in vivo. Gastrointest Endosc. 2009;70:362-68. 12. Sumiyama K, Kaise M, Kato M, Saito S, Goda K, Odagi I, et al. New generation argon plasma coagulation in flexible endoscopy: ex vivo study and clinical experience. J Gastroenterol Hepatol. 2006;21:1122-8. 13. Fujishiro M, Yahagi N, Nakamura M, Kakushima N, Kodashima S, Ono S, et al. Submucosal injection of normal saline may prevent tissue damage from argon plasma coagulation: an experimental study using resected porcine esophagus, stomach, and colon. Surg Laparosc Endosc Percutan Tech. 2006;16:307-11. 14. Fujishiro M, Yahagi N, Nakamura M, Kakushima N, Kodashima S, Ono S, et al. Safety of argon plasma coagulation for hemostasis during endoscopic mucosal resection. Surg Laparosc Endosc Percutan Tech. 2006;16:137-40. 15. Goulet CJ, Disario JA, Emerson L, Hilden K, Holubkov R, Fang JC. In vivo evaluation of argon plasma coagulation in a porcine model. Gastrointest Endosc. 2007;65:457-62. 16. Norton ID, Wang L, Levine SA Burgart LJ, Hofmeister EK, Yacavone RF, et al. In vivo characterization of colonic thermal injury caused by argon plasma coagulation. Gastrointest Endosc. 2002;55:631-6. 17. Fujishiro M, Kodashima S, Ono S, Goto O, Yamamichi N, Yahagi N, et al. Submucosal Injection of Normal Saline can Prevent Unexpected Deep Thermal Injury of Argon Plasma Coagulation in the in vivo Porcine Stomach. Gut Liver. 2008;2:95-8. 18. Grund KE, Straub T, Farin G. Clinical application of argon plasma coagulation in flexible endoscopy. Endosc Digest. 1998;10:1543-54. 19. Grund KE, Storek D, Farin G. Endoscopic argon plasma coagulation (APC) first clinical experiences in flexible endoscopy. Endosc Surg Allied Technol. 1994;2:42-6. 20. Manner H, May A, Rabenstein T, et al. Prospective evaluation of a new high-power argon plasma coagulation system (hp-APC) in therapeutic gastrointestinal endoscopy. Scand J Gastroenterol 2007; 42: 397-405 21. Sagawa T, Takayama T, Oku T, Pech O, Nachbar L, Enderle MD, et al. Argon plasma coagulation for successful treatment of early gastric cancer with intramucosal invasion. Gut. 2003;52:334-9. 22. Eickhoff A, Jakobs R, Schilling D, Hartmann D, Weickert U, Enderle MD, et al. Prospective nonrandomized comparison of two modes of argon beamer (APC) tumor desobstruction: effectiveness of the new pulsed APC versus forced APC. Endoscopy. 2007;39:637-42. 23. Kitamura T, Tanabe S, Koizumi W, Mitomi H, Saigenji K. Argon plasma coagulation for early gastric cancer: technique and outcome. Gastrointest Endosc. 2006;63:48-54. 24. Manner H, May A, Faerber M, Rabenstein T, Ell C. Safety and efficacy of a new high power argon plasma coagulation system (hp-APC) in lesions of the upper gastrointestinal tract. Dig Liver Dis. 2006;38:471-8. 25. Farooq FT, Wong RC, Yang P, Post AB. Gastric outlet obstruction as a complication of argon plasma coagulation for watermelon stomach. Gastrointest Endosc. 2007;65:1090-2. 26. Prost B, Poncet G, Scoazec JY, Saurin JC. Unusual complications of argon plasma coagulation. Gastrointest Endosc. 2004;59:929-32. 27. Kawada K, Kawano T, Momma K, Fujiwara J, Nagai K, Nishikage T, et al. New argon plasma coagulation method for superficial esophageal carcinomas: Argon plasma coagulation-subepithelial ablation. Dig Endosc. 2007;19:147-52. 28. Honda M, Hori Y, Nakada A, Uji M, Nishizawa Y, Yamamoto K, et al. Use of adipose tissue-derived stromal cells for prevention of esophageal stricture after circumferential EMR in a canine model. Gastrointest Endosc. 2011;73:777-84. 29. Wynn TA, Ramalingam 
TR. Mechanisms of fibrosis: therapeutic translation for fibrotic disease. Nat Med. 2012;18:1028-40. 30. Du Z, Wei C, Cheng K, Han B, Yan J, Zhang M, et al. Mesenchymal stem cell-conditioned medium reduces liver injury and enhances regeneration in reduced-size rat liver transplantation. J Surg Res.

2013;183:907-15. 31. Chen YX, Zeng ZC, Sun J, Zeng HY, Huang Y, Zhang ZY. Mesenchymal stem cellconditioned medium prevents radiation-induced liver injury by inhibiting inflammation and protecting sinusoidal endothelial cells. J Radiat Res. 2015;56:700-8.

\section{Figure Legends}

Figure 1. Explanatory figures of the pig esophagus and type $A$ and type $B$ injuries.

Histological control section of a normal pig esophagus showing the relevant layers of esophageal tissue (hematoxylin and eosin). Scale bars, $1 \mathrm{~mm}$.

Histological hematoxylin and eosin-stained cross-section of an esophageal wall and explanations of type $A$ and type $B$ injuries. Superficial tissue damage of the tunica mucosa was classified as type A damage, whereas type $B$ damage was defined as an injury pattern limited to the tunica muscularis. Histological findings of type B damage were eosinophilic and round-shaped change in muscle fibers with relatively large spaces between muscle fibers.

Scale bars, $1 \mathrm{~mm}$.

Figure 2. Histological sections showing the depths of damage caused by hybrid APC (A) and standard APC (B) and coagulation depths for hybrid APC and standard APC in various settings (C).

Settings of hybrid APC and standard APC (A and B): argon gas flow of $1.0 \mathrm{~L} / \mathrm{min}, 6$ seconds, at 40 watts.

Scale bars, $1 \mathrm{~mm}$.

AGF: argon gas flow, W: watts, CL: circular muscle layer, ML: Iongitudinal muscle layer, LPM: lamina propria mucosa, SM; submucosa, MM; muscularis mucosa.

Figure 3. Histological sections showing the non-atrophic muscle zone (Masson's trichrome staining) after hybrid APC (A) and after standard APC (B).

Settings of hybrid APC and standard APC: Argon gas flow of $1.0 \mathrm{~L} / \mathrm{min}, 1$ second, at 40 watts.

NAM, non-atrophic muscle zone. Scale bars, $1 \mathrm{~mm}$. ${ }^{*} p<0.05$ vs. hybrid APC.

Figure 4. Immunohistochemical analysis of the esophagus after APC at a gas flow of $1.0 \mathrm{~L} / \mathrm{min}$ for 1 second at $40 \mathrm{~W}$.

(A) Expression of a-smooth muscle actin (a-SMA).

(B) Expression of myeloperoxidase (MPO). 
(C) Expression of CD107a.

(D) Expression of CD31.

Scale bars, $50 \mu \mathrm{m} .{ }^{*} p<0.05$ vs. hybrid APC.

\section{Tables}

Due to technical limitations, tables 1 through 3 are only available as a download in the supplemental files section.

Figures 


\section{Figure 1}

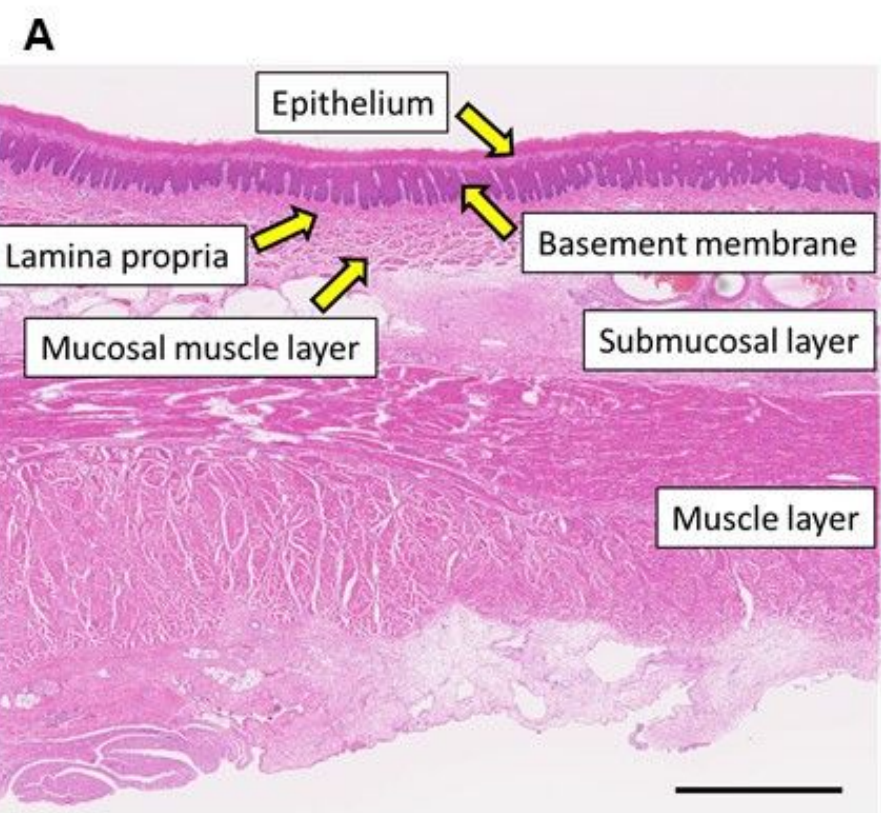

B

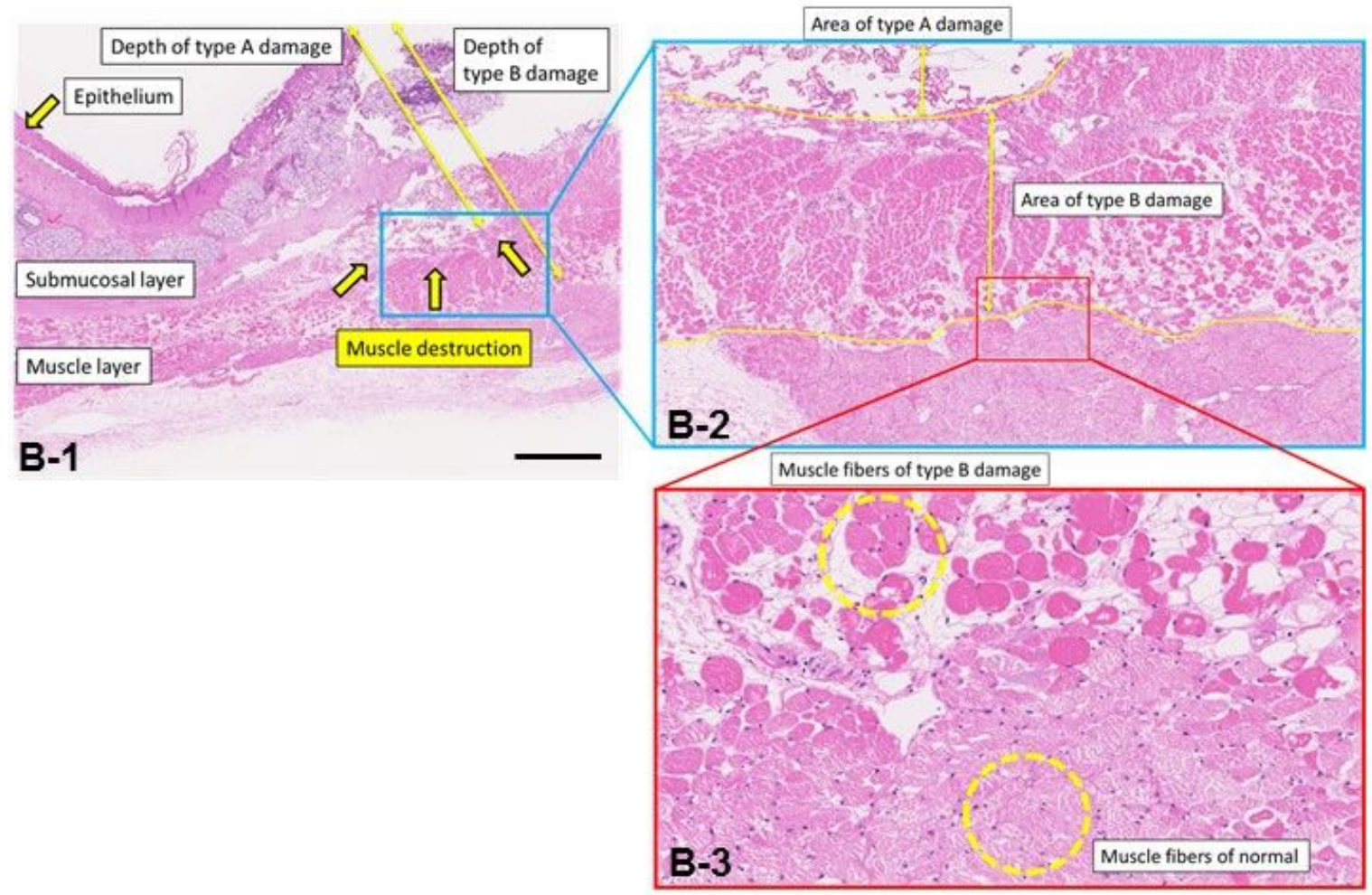

\section{Figure 1}

Explanatory figures of the pig esophagus and type $A$ and type $B$ injuries. (A) Histological control section of a normal pig esophagus showing the relevant layers of esophageal tissue (hematoxylin and eosin). Scale bars, $1 \mathrm{~mm}$. (B) Histological hematoxylin and eosin-stained cross-section of an esophageal wall and explanations of type $A$ and type $B$ injuries. Superficial tissue damage of the tunica mucosa was classified as type A damage, whereas type B damage was defined as an injury pattern limited to the 
tunica muscularis. Histological findings of type B damage were eosinophilic and round-shaped change in muscle fibers with relatively large spaces between muscle fibers. Scale bars, $1 \mathrm{~mm}$.

\section{Figure 2}

A

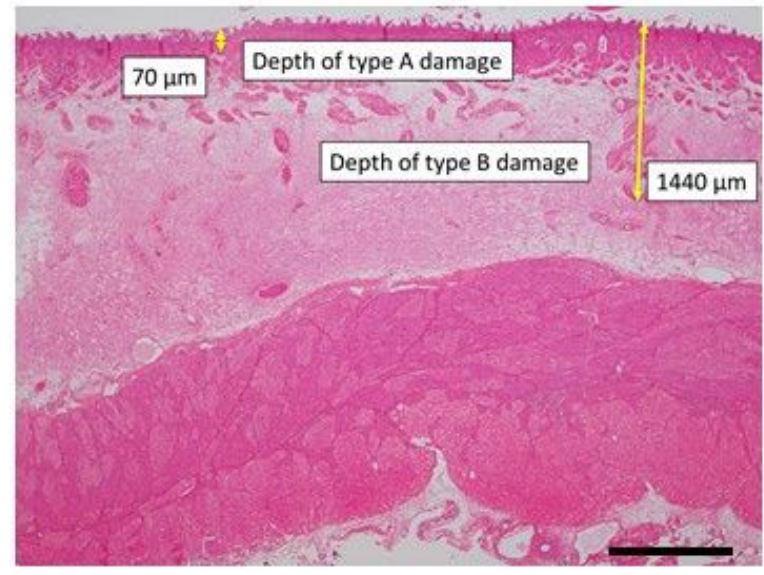

B

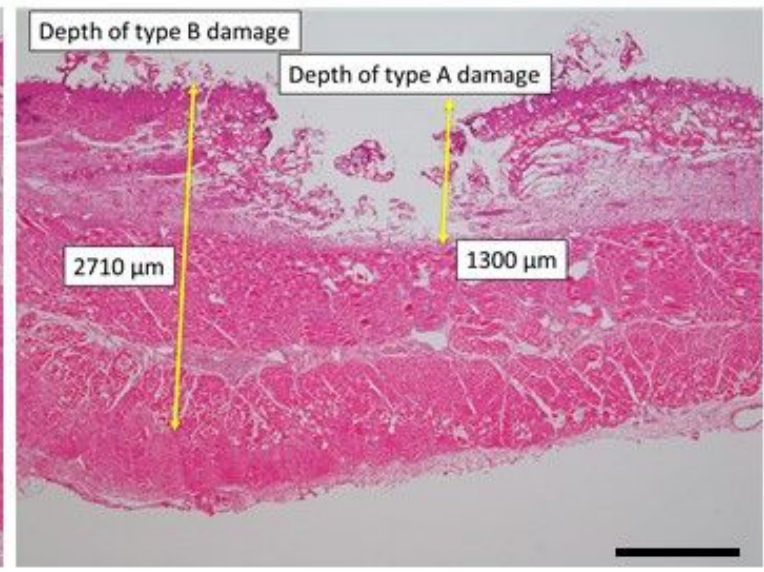

C

Hybrid APC: Type A damage

Hybrid APC: Type B damage

Standard APC: Type A damage

Standard APC: Type B damage

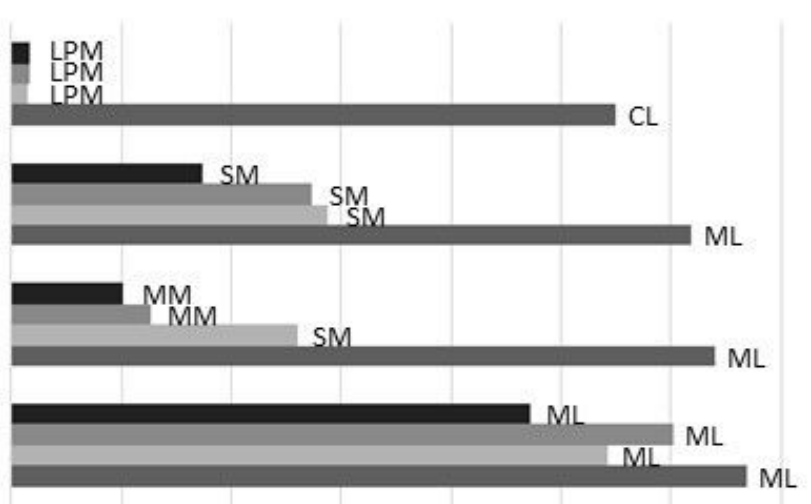

$\begin{array}{llllllll}0 & 500 & 1000 & 1500 & 2000 & 2500 & 3000 & 3500\end{array}$

- AGF of $1.0 \mathrm{~L} / \mathrm{min}, 3$ seconds, at $40 \mathrm{~W}$ m AGF of $1.0 \mathrm{~L} / \mathrm{min}, 4$ seconds, at $40 \mathrm{~W}$

m AGF of $1.0 \mathrm{~L} / \mathrm{min}, 6$ seconds, at $40 \mathrm{~W}=\mathrm{AGF}$ of $2.0 \mathrm{~L} / \mathrm{min}, 3$ seconds, at $60 \mathrm{~W}$

\section{Figure 2}

Histological sections showing the depths of damage caused by hybrid APC (A) and standard APC (B) and coagulation depths for hybrid APC and standard APC in various settings (C). Settings of hybrid APC and standard APC (A and B): argon gas flow of $1.0 \mathrm{~L} / \mathrm{min}, 6$ seconds, at 40 watts. Scale bars, $1 \mathrm{~mm}$. AGF: 
argon gas flow, W: watts, CL: circular muscle layer, ML: longitudinal muscle layer, LPM: lamina propria mucosa, SM; submucosa, MM; muscularis mucosa.

\section{Figure 3}

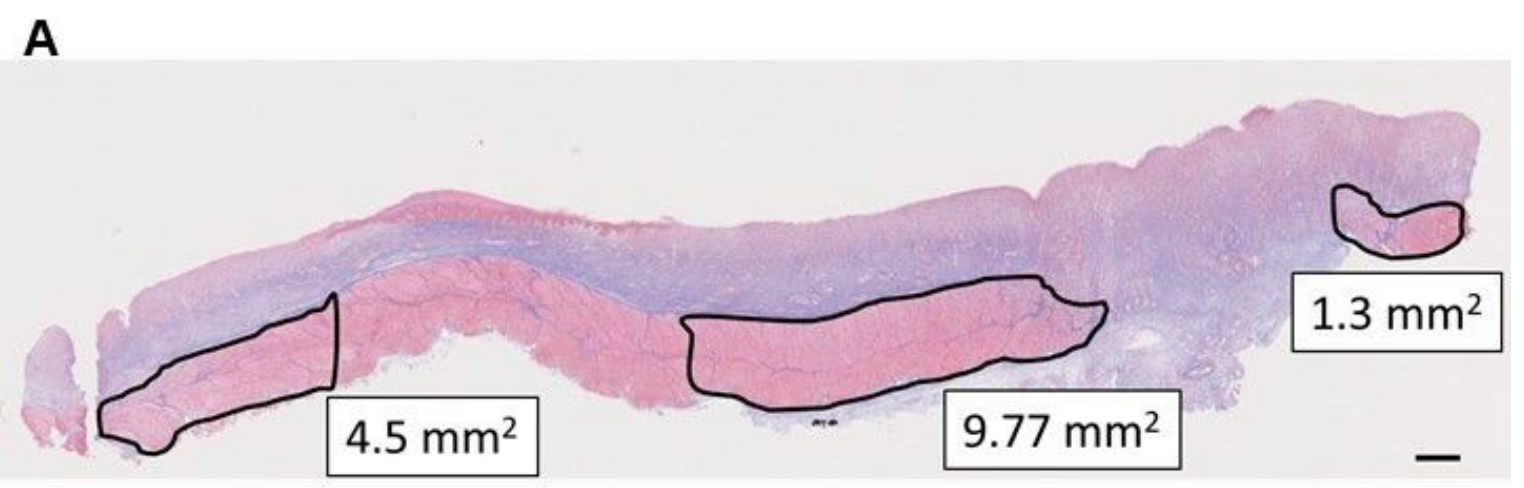

B

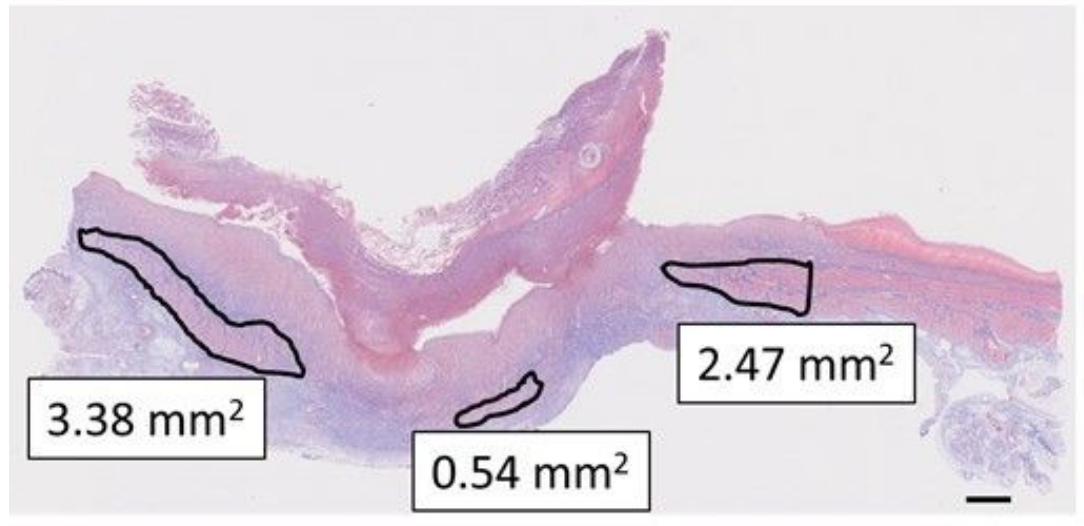

C

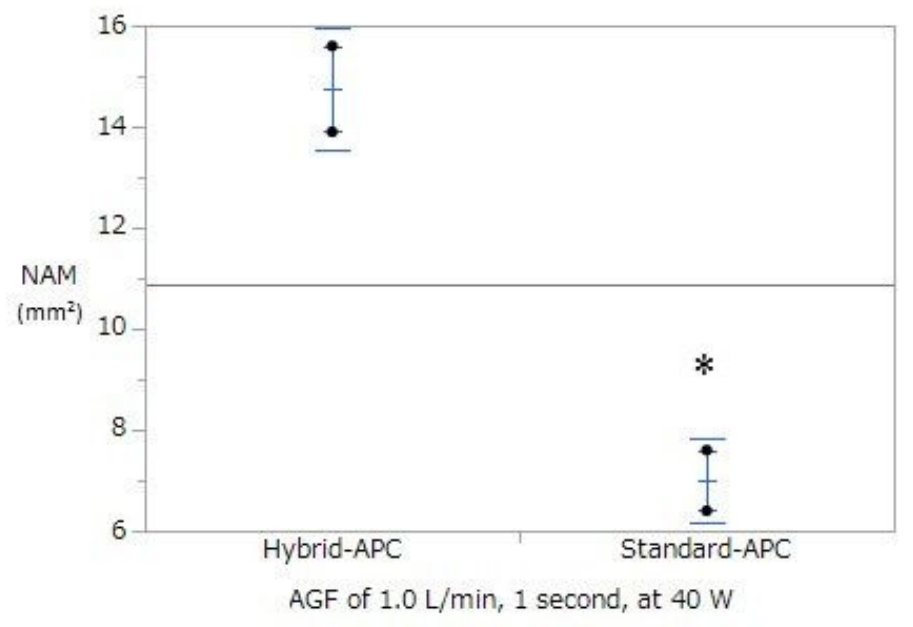

Figure 3

Histological sections showing the non-atrophic muscle zone (Masson's trichrome staining) after hybrid APC (A) and after standard APC (B). Settings of hybrid APC and standard APC: Argon gas flow of 1.0 
L/min, 1 second, at 40 watts. NAM, non-atrophic muscle zone. Scale bars, $1 \mathrm{~mm}$. ${ }^{*} p<0.05$ vs. hybrid APC.

\section{Figure 4}
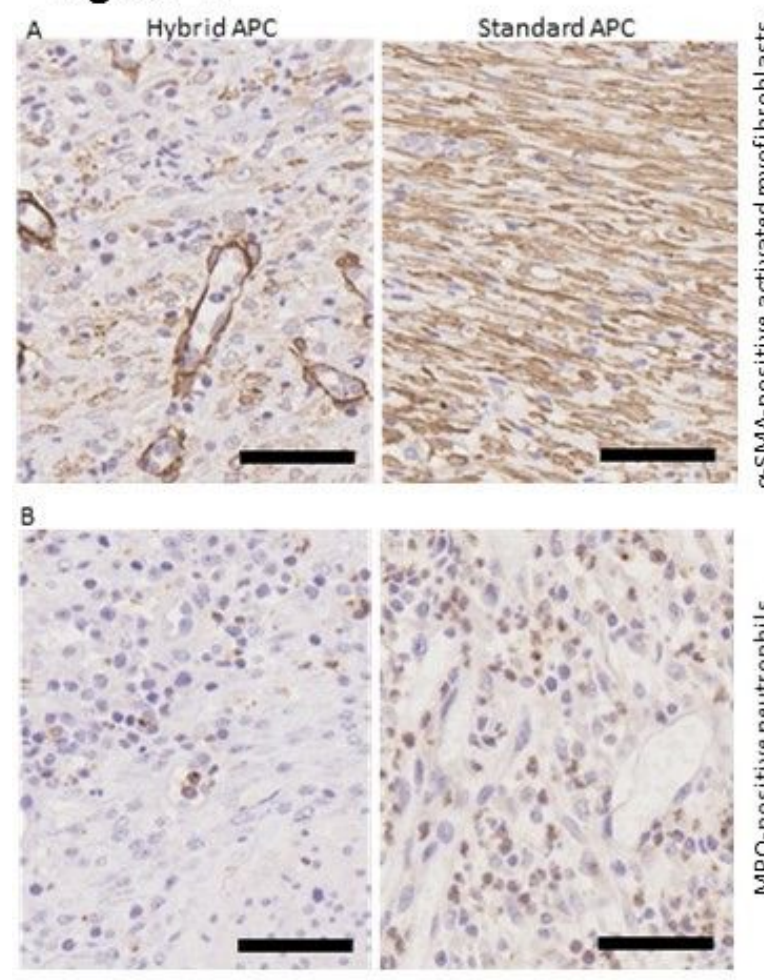

\section{c.}
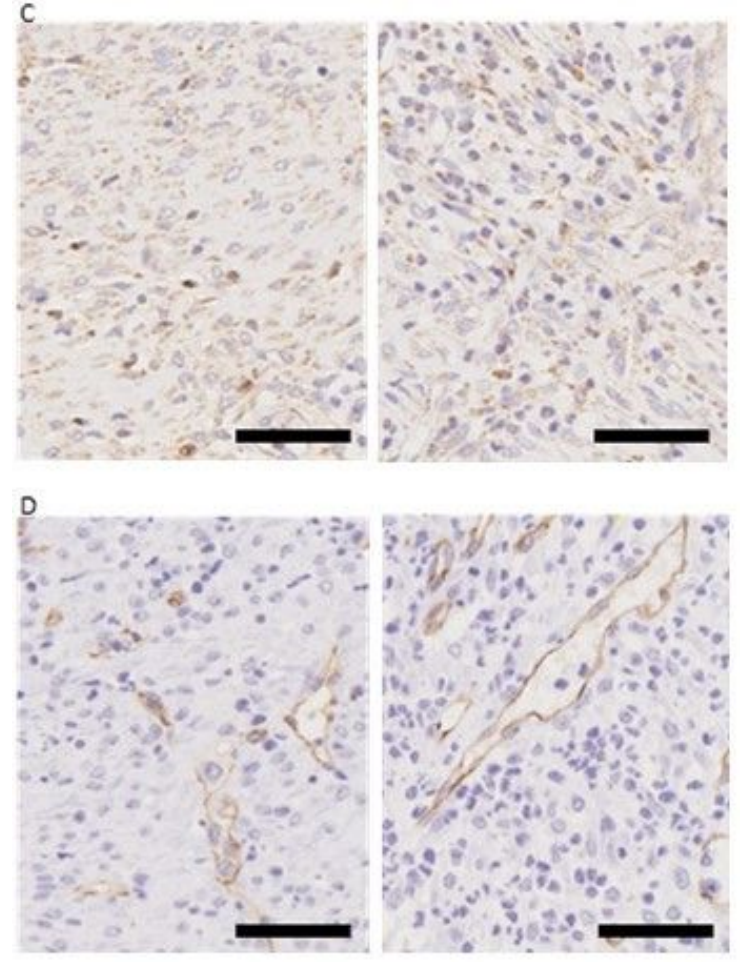
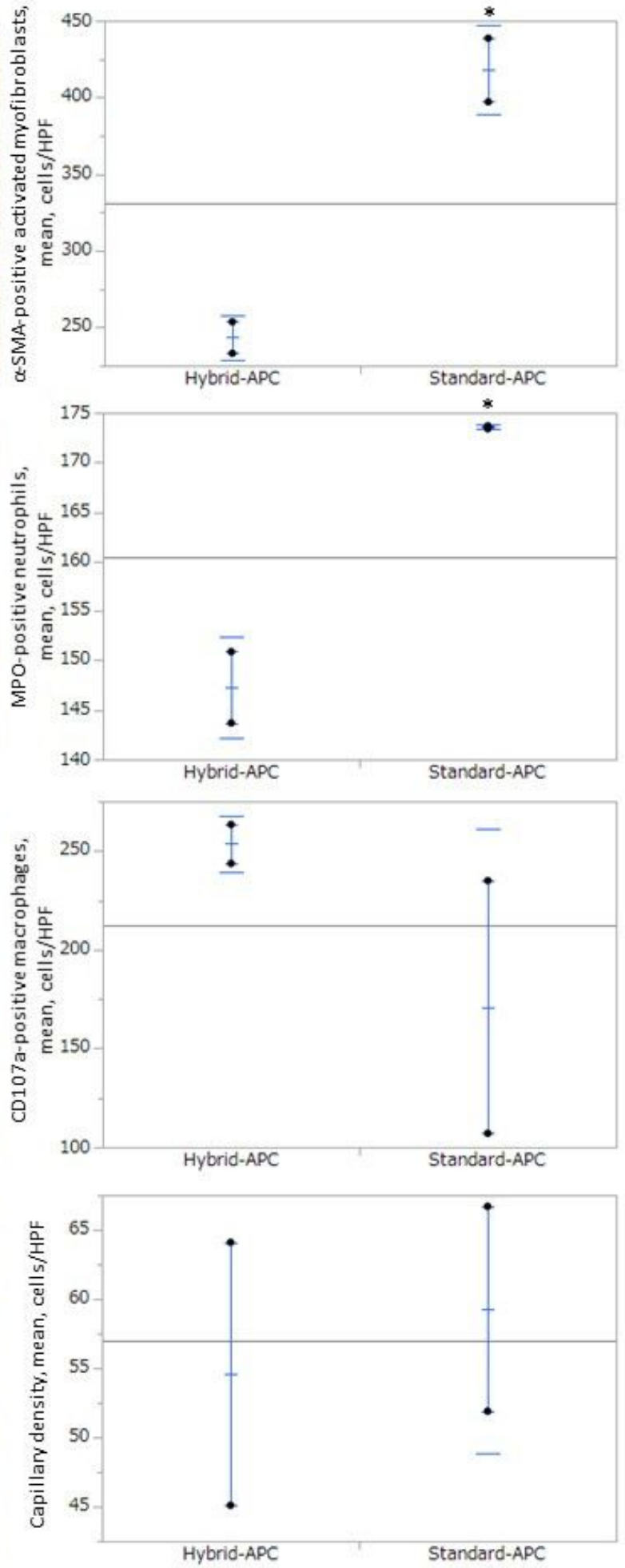

Figure 4

Immunohistochemical analysis of the esophagus after APC at a gas flow of $1.0 \mathrm{~L} / \mathrm{min}$ for 1 second at 40 W. (A) Expression of a-smooth muscle actin (a-SMA). (B) Expression of myeloperoxidase (MPO). (C) Expression of CD107a. (D) Expression of CD31. Scale bars, $50 \mu \mathrm{m}$. ${ }^{*}<<0.05$ vs. hybrid APC. 


\section{Supplementary Files}

This is a list of supplementary files associated with this preprint. Click to download.

- Table3.jpg

- Table2.jpg

- Table1.jpg 